\title{
Atividade de estudo: ferramenta para a constituição do autor nos anos iniciais do Ensino Fundamental
}

\author{
Learning activity: a tool to constitute authoring capacity in the \\ early years of Elementary School \\ Actividad de estudio: herramienta para constituir autoría en los
primeros años de la Escuela Primaria
}

\author{
Cleber Barbosa da Silva Clarindo* \\ STELA MILLER*
}

\begin{abstract}
RESUMO
Este artigo busca compreender, a partir do referencial da Teoria Histórico-Cultural, de que modo a atividade de estudo, como atividade principal das crianças em idade escolar inicial, pode ser ferramenta do processo de autoria. O homem, por sua atividade fundamental - o trabalho -, ao longo da história, constitui-se em ser transformador da natureza e produtor de cultura; pela atividade, ele produz e, nessa produção, também transforma suas capacidades de lidar com objetos da cultura humana. Daí se afirmar que os produtos de sua própria atividade caracterizam-se como atos de autoria. Nos anos iniciais do Ensino Fundamental, a atividade de estudo, como um tipo especial de prática que organiza e possibilita a formação de neoformações no psiquismo do sujeito, constitui-se em meio fundamental para o processo de desenvolvimento da capacidade de autoria.
\end{abstract}

Palavras-chave: Ensino Fundamental. Atividade de estudo. Autoria.

\begin{abstract}
This article aims to understand, from the framework of Cultural-Historical Theory, how the learning activity, the main activity of children in early school age, can be a tool of the authoring process. The man, for his fundamental work activity, throughout history, is constituted as a being that transforms nature and produces culture; by means of the activity, the man produces and, in this production, also transforms his ability to handle objects of human culture. Hence, we say that the products of his own activity are characterized as acts of authorship. In the early years of elementary school, the learning activity, as a special kind of activity that organizes and facilitates the formation of new formations in the psyche of the subject, is constituted as fundamental means in the process of developing the authoring capacity.
\end{abstract}

Keywords: Elementary School. Learning activity. Authoring capacity.

\section{RESUMEN}

Este artículo trata de comprender, desde el marco de la teoría histórico-cultural, como la actividad de estudio, la actividad principal de los niños en edad escolar temprana, puede ser una herramienta del proceso de creación. El hombre, por su actividad laboral fundamental, a lo largo de la historia, se constituye como transformador de la naturaleza y productor de cultura; por medio de la actividad, el hombre produce y, en esta producción, transforma también su capacidad para manejar objetos de la cultura humana. Por eso decimos que los productos de su propia actividad se caracterizan por actos de autoría. En los primeros años de la escuela primaria, la actividad de estudio, como un tipo especial de actividad que organiza y facilita la formación de nuevas formaciones en la psique del sujeto se constituye como un elemento central para el proceso de la capacidad de creación, de ser un autor.

Palabras clave: Escuela Primaria. Actividad de estudio. Autoría.

\footnotetext{
* Mestre em Educação pela Universidade Estadual Paulista pela Universidade Estadual Paulista Júlio de Mesquita Filho, Faculdade de Filosofia e Ciências - Unesp, Marília, SP. E-mail: <cleber clarindo@hotmail.com>.

** Doutora em Educação pela Universidade Estadual Paulista Júlio de Mesquita Filho e professora do Programa de Pós-Graduação em Educação da Faculdade de Filosofia e Ciências - Unesp, Marília, SP. E-mail: <stelamil@terra.com.br>.
} 


\section{INTRODUÇÃO}

A autoria é uma questão muito discutida nos meios acadêmicos. E a busca por compreender o que é ser autor perpassa várias áreas do saber científico e filosófico. Nota-se esse fato pelo grande número de autores que tem, de um modo ou de outro, como temática de seus estudos, essa questão. Pode-se dar como exemplos Foucault (2006), Orlandi (2000), Tfouni (2008), Silva (2008) e Miller (2003), que, em suas reflexões, dedicam-se ao tema em questão. Apesar da diferença de vertentes metodológicas, teóricas, ideológicas e abordagens que os caracteriza no tratamento da questão, esses autores buscam compreender o processo de constituição da autoria.

Nesse contexto, a questão da autoria não pode ser considerada uma discussão recente e nova no meio acadêmico, seja na área da linguística, da filosofia, seja na área da compreensão do processo pedagógico na constituição do autor. Mas ainda é frutífera em sua discussão pelo vasto campo de possibilidades de compreensão dos processos psicológicos humanos que essa problemática permite. Principalmente no campo didático-pedagógico, que é o centro da atenção deste estudo, já que a questão da autoria é um dos grandes problemas educacionais que afetam a formação dos escolares. Essa questão é tão evidente e marcante que seus reflexos não se limitam à educação básica; estes chegam de forma massificada até mesmo nas universidades, onde plágios, hoje, são cada vez mais noticiados, como afirma Silva (2008, p. 357).

O fato é que, historicamente, desde o ensino fundamental à universidade, se tem convivido com a prática de cópias de produções textuais de outrem, de forma parcial ou total, omitindo-se a fonte. No contexto da sociedade informatizada em que vivemos, essas discussões têm-se acentuado, haja vista as possibilidades que se vêm ampliando, pela internet, no que diz respeito ao graduando apropriar-se de obras protegidas por direitos autorais.

Partindo dessa constatação, este artigo busca fazer uma reflexão teórica sobre o processo de autoria entre os alunos dos anos iniciais do Ensino Fundamental. Tal reflexão se justifica por se entender que, nessa etapa da vida infantil, deveriam ocorrer transformações essenciais nos modos de os escolares se relacionarem com a realidade. Isso porque a idade escolar tem como atividade diretora a prática do estudo, que, por meio dos conhecimentos teóricos, guia todo o desenvolvimento das crianças nessa etapa de sua vida. Antes disso, na idade pré-escolar, elas relacionam-se com o mundo por meio do jogo de papéis sociais, que orienta e dirige os processos de seu desenvolvimento. Como assegura Elkonin (1987, p. 108 , tradução do pesquisador):

[...] pode-se dizer que cada estágio do desenvolvimento psíquico se caracteriza pela relação determinada, diretora na etapa dada, da criança com a realidade, por um tipo determinado, diretor de atividade.

O sintoma da passagem de um estágio a outro é precisamente a mudança do tipo diretor da atividade, da relação diretora da criança para a realidade.

É o que ocorre, por exemplo, com a passagem da criança da idade pré-escolar para a escolar. Sua entrada na escola traz novos desafios, pois há uma mudança qualitativa na relação que ela mantém com seu meio, e novas relações sociais são introduzidas em sua vida. Com isso, alteram-se seus vínculos com grupos de estudantes, com familiares, com os objetos culturais que se ampliam por força de seu novo relacionamento com a cultura sistematizada presente no currículo escolar. Sua nova atividade passa, então, a ser a prática de estudo, que gera transformações revolucionárias em suas relações com o mundo humano. Transformações essas pautadas pelos conhecimentos científicos, que possibilitam às crianças o desenvolvimento do pensamento teórico, fruto do processo criativo humano exercido ao longo do avanço histórico e social. Evolução que possibilitou ao homem sair dos limites das relações imediatas com o mundo.

Ao se compreender o processo de desenvolvimento do homem como resultado de sua própria atividade, defende-se a ideia de que a questão da autoria é fruto do agir humano na transformação da realidade, ou seja, ser autor é estar em atividade.

\section{ATIVIDADE COMO FORMA TIPICAMENTE HUMANA DE AUTORIA}

A necessária compreensão do que se considera autoria e suas implicações nos processos pedagógicos implica, antes de tudo, a sistematização e o esclarecimento de um conceito fundamental das bases teóricas do materialismo dialético presentes na Teoria Histórico-Cultural, referência deste trabalho: a atividade. Esse conceito, como categoria filosófica fundamental que corresponde à categoria trabalho, segundo a tradição marxista, refere-se à atividade que está na base do desenvolvimento de todas as grandes conquistas humanas. É pela atividade que o homem exerce a transformação criativa da realidade.

No devir da história, o trabalho se constituiu em atividade fundamental humana, produzindo as condições para o desenvolvimento de ferramentas e meios de produção necessários à transformação da natureza. E, consequentemente, em um movimento dialético para a transformação do próprio homem, que, no processo 
produtivo, torna-se ser do gênero humano, desenvolvendo as aptidões necessárias à apropriação e construção de novas formas de meios de produção.

Pode-se distinguir os homens dos animais pela consciência, pela religião e por tudo o que queira. Mas eles próprios começam a se distinguir dos animais logo que começam a produzir seus meios de existência, e esse passo à frente é a própria conseqüência de sua organização corporal. Ao produzirem seus meios de existência, os homens produzem indiretamente sua própria vida material.

A maneira como os homens produzem seus meios de existência depende, antes de mais nada, da natureza dos meios de existência já encontrados e que eles precisam reproduzir. Não se deve considerar esse modo de produção sob esse único ponto de vista, ou seja, enquanto reprodução da existência física dos indivíduos. Ao contrário, ele representa, já, um modo determinado da atividade desses indivíduos, uma maneira determinada de manifestar sua vida, um modo de vida determinado (MARX e ENGELS, 2002, p. 10-11).

É, portanto, no processo do trabalho, que o homo sapiens sai dos limites deterministas das necessidades estritamente biológicas e conhece as possibilidades ilimitadas do desenvolvimento baseado nas relações sociais humanas. Como afirma Leontiev (2004, p. 280), a “[...] hominização resultou da passagem à vida numa sociedade organizada na base do trabalho". Para o autor, essa nova etapa das relações humanas com a realidade "[...] marcou o início de um desenvolvimento que, diferentemente do desenvolvimento dos animais, estava e está submetido não às leis biológicas, mas a leis sócio-históricas". Ao livrarse dos limites biológicos para o desenvolvimento pautado nos processos histórico-culturais, o homem realiza seu primeiro ato humano de autoria.

Tal afirmação permite que se entenda a função primordial da atividade no processo de organização e constituição do homem como ser histórico, proveniente de suas relações com outros homens e com os objetos produtos de sua atividade. Leontiev, ao estudar as particularidades e influências da atividade no desenvolvimento das aptidões e capacidades humanas, afirma que:

Ao mesmo tempo no decurso da atividade dos homens, as suas aptidões, os seus conhecimentos e o seu saberfazer cristalizam-se de certa maneira nos seus produtos (materiais, intelectuais, ideais). Razão por que todo o progresso no aperfeiçoamento, por exemplo, dos instrumentos de trabalho pode considerar-se, deste ponto de vista, como marcando um novo grau do desenvolvimento histórico nas aptidões motoras do homem; também a complexidade da fonética das línguas encarna os progressos realizados na articulação dos sons e do ouvido verbal, os progressos das obras de arte, um desenvolvimento estético etc. (LEONTIEV, 2004, p. 283-284).
O processo de cristalização das atividades humanas nos bens produzidos pela humanidade possibilita às novas gerações apropriarem-se da cultura das gerações anteriores, ou seja, é no produto do trabalho, em um processo ativo, que as novas gerações se apoiam para reproduzir, apropriar e criar novos bens culturais. Além de, dialeticamente, ter novas habilidades, capacidades e aptidões para lidar com a realidade. Pela aprendizagem e apropriação do mundo dos bens culturais, o homem se torna humano, pois o que a natureza lhe oferece é limitado e insuficiente para viver em sociedade. "É-lhe ainda preciso adquirir o que foi alcançado no decurso do desenvolvimento histórico da sociedade humana" (LEONTIEV, 2004, p. 285).

O indivíduo é colocado diante de uma imensidade de riquezas acumuladas ao longo dos séculos por inumeráveis gerações de homens, os únicos seres, no nosso planeta, que são criadores. As gerações humanas morrem e sucedem-se, mas aquilo que criaram passa às gerações seguintes que multiplicam e aperfeiçoam pelo trabalho e pela luta as riquezas que lhe foram transmitidas e "passam o testemunho" do desenvolvimento da humanidade (LEONTIEV, 2004, p. 285 , grifos no original).

Lida-se, então, com a compreensão de que o processo educativo é um encadeamento histórico e ativo dentro de uma determinada sociedade que tem seus costumes, regras, tipos de pensamentos, modos de agir; e o desenvolvimento dos indivíduos se dá a partir de suas atividades concretas realizadas no âmbito das reais condições materiais de sua vida. A autoria é fruto desses processos, ou seja, o desenvolvimento dessa capacidade é determinado pelas condições históricas e sociais que marcam a vida do sujeito em determinadas relações por ele estabelecidas em seu meio, em uma dada época. E isso só é possível se o sujeito estiver em atividade criativa, autoral.

Pode-se, dessa forma, afirmar que a autoria só pode ser efetivada em uma atividade e de acordo com o lugar que o sujeito ocupa nas relações sociais, compreendendo que esta não se efetiva de modo mecânico, mas decorre de estruturas complexas que se relacionam dialeticamente no processo de desenvolvimento humano.

\section{A ESTRUTURA DA ATIVIDADE}

Inicialmente, destaca-se o fato de que a atividade humana está sempre vinculada a um motivo. Leontiev (1978, 2004, 2006) assegura que sem motivo não há atividade, e que toda atividade, objetiva ou subjetivamente, tem sua motivação.

O componente da atividade que concretiza o agir humano é a ação. Esta, como parte da estrutura da atividade, 
tem como característica ser um processo determinado por um fim consciente. Sua função é de orientação: as ações que executam a atividade, embora estejam orientadas, cada uma delas, por um objetivo que não coincide com o motivo da atividade, são impulsionadas, desde o início, por esse motivo. Em outras palavras, cada ação tem seu objetivo próprio, porém, no seu conjunto, as ações são impulsionadas pelo motivo que gerou a atividade e se dirigem à obtenção de sua finalidade.

As ações se caracterizam por dois aspectos constitutivos: o primeiro, já posto acima, seu caráter intencional, ou seja, os sujeitos das ações têm sempre consciência de seu objeto (o que deve ser conseguido); o segundo aspecto é o operacional, que tem como base os modos, os meios e as ferramentas para se chegar a esse objeto (por qual meio pode ser conseguido o objeto).

Esse último aspecto revela o elemento efetor das ações, isto é, as operações destinadas à execução das ações, dentro de certas condições dadas. As operações são, portanto, "os meios com os quais se executa a ação" (LEONTIEV, 1978, p. 85). Ações e operações são, como se vê, processos que se diferenciam, pois as ações são condicionadas pelos seus objetivos, e as operações, pelas condições de realização das ações. Entretanto, não se pode separar ação e operação; apesar de diferentes origens e funções, estas se caracterizam como partes de um todo constituído na atividade, como cadeia de ações realizadas em determinadas condições. Leontiev resume o processo de análise do disposto acima da seguinte forma:

[...] no fluxo geral da atividade que configura a vida humana em suas manifestações superiores, mediatizadas pelo reflexo psíquico, a análise delimita, primeiro, algumas atividades (especiais), segundo o critério dos motivos que as impulsionam. Logo se delimitam as ações, ou processos que obedecem a fins conscientes. Por último, estão as operações que dependem diretamente das condições requeridas para alcançar o fim concreto (LEONTIEV, 1978, p. 87, tradução do pesquisador).

\section{OS DIFERENTES TIPOS DE ATIVIDADES}

Estudos sobre a periodização do desenvolvimento infantil foram aprofundados por Elkonin. $\mathrm{O}$ autor partiu dos conhecimentos elaborados inicialmente por Vigotski, nos anos de 1930, sobre o problema das etapas do desenvolvimento infantil, e, principalmente, pelas contribuições de Leontiev ao transformar os rumos da compreensão das forças motrizes que produzem e desenvolvem o psiquismo humano, com a introdução do exame das funções psíquicas e da consciência pelo conceito de atividade (ELKONIN, 1987 Buscou ainda as raízes das mudanças e dos trânsitos das atividades que caracterizam os diferentes modos pelos quais os sujeitos lidam com a realidade. Nesse sentido, Elkonin afirma que:

[...] Na realidade, o desenvolvimento psíquico não pode ser compreendido sem uma profunda investigação do aspecto objetal de conteúdo da atividade, ou seja, sem esclarecer com que aspectos da realidade interage a criança em uma ou outra atividade e, em consequência, para que aspectos da realidade se orienta (ELKONIN, 1987, p. 109, tradução do pesquisador).

É no processo constante de apropriação, pela atividade, das relações sociais e em sua complexificação ao longo da vida que está baseada a teoria da periodização de Elkonin. Pelas atividades que ocorrem em cada fase da vida dos sujeitos e principalmente pelos trânsitos de uma a outra, é possível analisar as características do desenvolvimento humano. O conceito de periodização implica a compreensão de que cada etapa do desenvolvimento psíquico humano tem uma atividade que dirige a relação do sujeito com o mundo.

Assim é que, em seu primeiro ano de vida, a atividade diretora do desenvolvimento da criança é a comunicação emocional direta, decorrente da relação comunicativa e afetiva das crianças com os adultos que dela cuidam. Essa interação permite às crianças pequenas entrar em contato com o mundo das relações humanas, formando nelas as ações de orientação e as sensório-motoras. São essas apropriações que serão a base para a próxima atividade principal.

A atividade objetal manipulatória da criança encontrase no período da primeira infância. Nessa etapa do seu desenvolvimento, ela se apropria dos procedimentos, socialmente elaborados, das ações com os objetos, em cujo processo ela compara suas ações com as dos adultos, o que torna possível, segundo Elkonin (1987, p. 117, tradução do pesquisador), "a penetração das crianças nas tarefas e no sentido das ações humanas".

O jogo de papéis sociais é a atividade da criança em idade pré-escolar; é na atividade do jogo que ela se apropria das relações mais gerais da sociedade humana. A partir da reprodução dos papéis sociais, a criança assimila o mundo dos adultos e modela as relações da vida humana. É na necessidade de apropriação das relações das variadas atividades humanas que está a origem da atividade das crianças em idade pré-escolar, ou, como afirma Elkonin (1986, p. 77, tradução do pesquisador): “A especial sensibilidade do jogo à esfera da atividade humana e às relações entre os homens mostra que, apesar de toda variedade de argumentos, por trás deles se encontra um mesmo conteúdo: atividade humana e as relações dos homens na sociedade" (ELKONIN, 1986, p. 77, tradução do pesquisador). 
A necessidade de conhecer as relações das atividades humanas leva a criança a buscar a compreensão da essência dessas práticas, gerando nela o interesse pela busca dos conhecimentos que lhe deem tal compreensão. Nesse contexto, a entrada da criança na escola tem um papel fundamental na transformação de sua atividade principal. É a atividade de estudo que vai governar na idade escolar o desenvolvimento das crianças. É por meio dessa atividade diretora que as crianças, nessa etapa do desenvolvimento humano, reproduzem os conhecimentos, habilidades e capacidades produzidas historicamente pela humanidade, tendo como base uma nova forma de pensamento, o pensamento teórico.

No período da adolescência, geralmente ocorre a atividade de comunicação íntima pessoal, que decorre do processo de relações e comunicações com outros adolescentes (constantemente marcado pela formação de grupos), bem como com outras pessoas. Isto é, a necessidade de os adolescentes estarem em grupos sociais com seus pares possibilita a reprodução das relações de companheirismos fundamentais para formação de sua personalidade. Pela atividade de comunicação íntima pessoal, o adolescente apropria-se dos códigos de conduta e das normas morais e éticas que vão coordenar seus atos nas relações com o mundo.

Construída sobre a base da completa confiança e comunidade da vida interna, a comunicação pessoal constitui aquela atividade dentro de que se formam os pontos de vista gerais sobre a vida, sobre as relações entre pessoas, e o próprio futuro; em uma palavra, se estrutura o sentido pessoal da vida. Na comunicação se forma a autoconsciência como "consciência social internalizada" (L. Vigotski). Graças a isto surgem as premissas para que se originem novas tarefas e motivos da atividade conjunta, a que se converte na atividade dirigida ao futuro e adquire o caráter de atividade profissional-de estudo (ELKONIN, 1987, p. 121, tradução do pesquisador, grifo do autor).

Todos esses esforços de conhecer a atividade, entendendo origem, particularidades, organização, sua estrutura e sua periodização, são de fundamental importância para compreender o objeto de análise, no caso deste artigo, o papel da atividade de estudo como ferramenta para constituição do autor.

\section{ATIVIDADE DE ESTUdO COMO FERRAMENTA ORGANIZATIVA DA FORMAÇÃO DO AUTOR}

Primeiramente, é preciso deixar claro que a atividade de estudo se diferencia de outras atividades pelo seu objetivo e resultado. Distingue-se pelo seu objetivo, pois, diferentemente de outras atividades, na prática de estudo as mudanças não estão dirigidas aos objetos com que o indivíduo atua ou que ele manipula e sim a ele próprio. Consequentemente, o resultado é a transformação do próprio sujeito. É por esse contexto que se afirma que prática de estudo é a atividade em que o sujeito se autotransforma, toma consciência de suas necessidades, torna-se sujeito real da atividade, ou seja, torna-se autor de sua vida.

Compreender a ideia de prática de estudo como autotransformação é, antes de tudo, entender o caráter histórico das atividades anteriores da vida humana como o resultado do processo de se tornar sujeito destas. Isto é, todo o processo de desenvolvimento de uma pessoa é fruto de diversificados modos e formas de atividade humana. O desenvolvimento intelectual só é possível na medida em que o homem se apropria de agregados e de sistemas de atividades; é nesses processos que o indivíduo se faz realmente sujeito, ou seja, ele só se efetiva na e em atividade.

Como qualquer atividade, a de estudo não se dá mecanicamente; realiza-se quando a criança sente a necessidade de se apropriar dos conhecimentos teóricos, como resposta a alguma exigência. Se não existe essa condição e a consequente busca do objeto que a satisfaça e seu encontro, não aparece o motivo para agir, e a atividade não surge, não acontece e não se efetiva. Nos vários sistemas e modos de atividade humana, desenvolvem-se e surgem novas e diversificadas formas de necessidade. Cada tipo de atividade é, a priori, uma exigência. Assim, no início da idade escolar, não se configura como natural para criança a necessidade psicológica de apropriação dos conteúdos teóricos, o que ocorre com a mediação do professor, nas ações essencialmente voltadas para o estudo (DAVIDOV, 1988, p. 178).

Paulatinamente, os pré-escolares de maior idade começam a necessitar de fontes mais amplas de conhecimento que lhe oferecem a vida cotidiana e o jogo. Na presença do ensino escolar geral o pré-escolar deixa de sentir-se satisfeito com o modo habitual de vida e deseja ocupar a posição de escolar ("quero ir à escola", "quero estudar na escola", etc.).

$\mathrm{O}$ ingresso à escola permite à criança sair dos limites do período infantil de sua vida, ocupar uma nova posição e passar ao cumprimento da atividade de estudo, socialmente significativa, que oferece um rico material para satisfazer seus interesses cognitivos. Esses interesses atuam como premissas psicológicas para que surja na criança a necessidade de assimilar conhecimentos teóricos (DAVIDOV, 1988, p. 177-178, tradução do, pesquisador, grifos do autor).

Uma vez surgida a necessidade de encontrar explicações mais consistentes para situações e fatos que cercam a criança em seu meio, compreende-se que 
ela busca encontrar um objeto (material ou ideal) que possa satisfazer essa necessidade; não mais bastam os conhecimentos empíricos construídos sobre as representações que mostram a aparência dos fenômenos. A criança quer explicações que vão além, isto é, que desvelem a essência dos fenômenos; daí ser o conhecimento teórico o conteúdo da atividade de estudo. No processo de formação da necessidade de apropriação dos conhecimentos científicos, o motivo para os escolares se apropriarem dos rudimentos das ciências está no próprio conhecimento científico ou, nas palavras de Davidov (1988, p. 178, tradução do pesquisador), “[...] os conhecimentos teóricos, constituindo o conteúdo da atividade de estudo, são simultaneamente sua necessidade".

Por motivo, entende-se o encontro com um objeto que é suficientemente capaz de satisfazer uma necessidade. Toda atividade tem motivos específicos, que estão relacionados à necessidade. Portanto, para a efetivação de uma atividade, deve-se configurar um motivo. Nas palavras de Leontiev (1978, p. 82, tradução do pesquisador, grifos do autor), "não há atividade sem motivo; a atividade "não motivada' não é uma atividade carente de motivo e sim uma atividade com motivo subjetiva e objetivamente oculto". Os motivos no processo de atividade desempenham dois papéis funcionais: o primeiro está relacionado ao estímulo para atividade, ou seja, o objeto reconhecido como aquele que vai satisfazer a necessidade transforma-se no motivo, no estopim para o sujeito agir; o segundo tem a função de constituição de significado, o que dá ao sujeito sentido para suas ações. Segundo Marino Filho (2011, p. 125):

[...] a motivação ocupa um importante papel de orientação pessoal para a assunção de uma atividade. Se a necessidade é estruturante da atividade, a motivação, por sua vez, indica as possibilidades de efetivação da atividade, ou a forma como essa se desenvolverá. Portanto, os aspectos sobre a formação de motivos tornam-se importantes na atividade pedagógica, para que se possa articular a formação de sentidos para a vinculação com a atividade escolar.

Somente na troca de atividades é que se percebe o processo de origem de um motivo. Este pode originar-se de duas formas: de maneira externa, quando não é criado pela atividade; e de maneira interna, quando tem sua gênese na atividade como apontam Leontiev (1978) e Marino Filho (2011).

"O objeto da atividade - afirma Leontiev (1978, p. 82) - é seu verdadeiro motivo." Desse ponto de vista, na atividade de estudo, o motivo para satisfazer a necessidade dos alunos é o conhecimento científico; ou seja, o próprio objeto de estudo constitui-se no motor para reprodução dos procedimentos do pensamento teórico. É nesse processo que as crianças em idade escolar têm o domínio dos procedimentos e da estrutura de determinado conceito. Davidov ajuda a entender esse processo quando afirma que:

\begin{abstract}
Os motivos das ações de estudo impulsionam os escolares a assimilar os procedimentos de reprodução dos conhecimentos teóricos. Durante o cumprimento das ações de estudo os escolares dominam, principalmente, os procedimentos de reprodução de uns ou outros conceitos, imagens, valores e normas concretos e, através desses procedimentos, assimilam o conteúdo de tais conhecimentos teóricos (DAVIDOV, 1988, p. 178, tradução do pesquisador).
\end{abstract}

Em resumo, os motivos são a concretização da atividade de estudo, o que consequentemente impulsiona as crianças a se apropriarem dos conhecimentos teóricos; e os motivos têm a função diretora dos procedimentos pela via das ações de estudo. que têm como fim, dentro das condições dadas, resolver uma determinada tarefa de estudo.

A tarefa é, nesse contexto, a unidade entre o objetivo da ação e as condições em que esse objetivo é alcançado, ou seja, a tarefa surge como condição concreta de realização de um objetivo. Conceitualmente, este, para a teoria histórico-cultural, é o determinante direto que produz atividade, regulando suas formas e seus meios. Por isso, pode-se dizer que toda atividade, por sua concretude de objetivos, é sempre um procedimento de solução de tarefas.

Como unidade do objetivo da ação de estudo com as condições de realização da atividade, a tarefa exige do escolar a análise do propósito dessa atividade. E a finalidade é descobrir as relações gerais desse objeto e compreender as leis dos diferentes tipos de sua manifestação, culminando na construção de abstrações e generalizações. É por esse motivo que, na aplicação da tarefa de estudo, vai se dar a dedução das relações particulares do objeto, consolidando-se o processo de síntese e configurando mentalmente sua célula. Por célula, entende-se o processo que estabelece a unidade entre o singular e o universal do que realmente existe e que faz a ligação das particularidades com o todo do material estudado.

Nesse contexto, entende-se que o objetivo da tarefa de estudo não se restringe apenas ao domínio dos modos de ação, mas sim à apropriação dos fundamentos teóricos que os sustentam, isto é, o domínio dos princípios de ação.

Durante a solução da tarefa escolar os alunos descobrem a origem da "célula" do objeto integral estudado e, utilizando-a, reproduzem mentalmente esse objeto. Com isso, na solução da tarefa escolar, os alunos realizam certo microciclo de ascensão do abstrato ao concreto como via de assimilação dos conhecimentos teóricos. 
A tarefa de estudo se diferencia essencialmente das diversas tarefas particulares de um ou outro tipo. Se resolverem tarefas particulares, os escolares vão dominar os procedimentos também particulares de sua solução e só o treinamento permite dominar certo procedimento geral para solucionar ditas tarefas. A assimilação deste procedimento tem lugar pela via da passagem do pensamento do particular ao geral. Em contrapartida, quando os escolares resolvem a tarefa de estudo, eles dominam inicialmente o procedimento geral de solução das tarefas particulares. A solução da tarefa escolar é importante não só para o caso particular dado, mas para todos os casos do mesmo tipo. Aqui o pensamento dos escolares se move do geral ao particular (DAVIDOV, 1988, p. 179, tradução do pesquisador).

Fica evidenciado que, na atividade de estudo, os modos de ação são superados dialeticamente pelos princípios de ação; são dois processos diferentes, mas que se inter-relacionam na atividade.

Os princípios de ação possibilitam que o sujeito da atividade, de forma autônoma, crie seus próprios conjuntos de ações. Quando uma pessoa se apropria de princípios de ação, ela se torna criadora; há o aspecto criativo no princípio de ação. Ao criar, o indivíduo se transforma em sujeito real da atividade.

Contrariamente, apenas dominar o modo de ação faz do sujeito um reprodutor mecânico de relações; apropriarse do modo de ação não causa transformação no sujeito, ou seja, não há verdadeira atividade de estudo quando apenas ocorre a apropriação de modos de ação. Em resumo, a grande diferença entre os modos de ação e os princípios de ação está na possibilidade de os princípios criarem no sujeito a capacidade de descobrir e buscar com autonomia os modos para solucionar um vasto e amplo conjunto de tarefas.

Ressalta-se que a apropriação do princípio de ação também se diferencia da apropriação do modo de ação. Não é possível dominar um princípio por meio de demonstrações, repetições de exercícios, como ocorre na apropriação dos modos de ação. Para apropriação dos princípios de ação, é necessário que o sujeito os abstraia e os generalize. Ele deve analisar as relações existentes, chegando aos fundamentos das ações. Nesse processo, há a formação de mecanismos de generalização e análise. No caso da atividade de estudo, os fundamentos que devem ser dominados são os de generalização teórica, criando habilidades teóricas para lidar com o mundo.

Portanto, a atividade de estudo, por sua estrutura e processos demonstrados até o momento, tem, como resultados para o desenvolvimento dos estudantes, a apropriação dos conhecimentos teóricos e a formação do pensamento teórico. Este consequentemente permite o domínio e a produção dos princípios de ação do pensamento teórico, além da capacidade de realizar ações teóricas no âmbito do mundo dos conhecimentos humanos. Aqui se encontra a especificidade da atividade de estudo em possibilitar a apropriação pelos indivíduos de habilidades para produzir capacidades humanas, processo nunca visto antes na história do desenvolvimento ontogênico da criança. Por essa razão, a atividade de estudo é considerada um prática criadora $\mathrm{e}$ autotransformadora do sujeito.

A atividade de estudo, por sua essência, está ligada com o pensamento produtivo (ou criador) dos escolares. Ao mesmo tempo, os especialistas consideram que os trabalhos criativos autônomos se organizam, na atualidade, durante o estudo de qualquer das disciplinas escolares nas séries iniciais. No cumprimento de tal esforço, as crianças realizam necessariamente a pesquisa autônoma do caminho para solucionar a tarefa, examinam suas possíveis variantes. "Semelhantes trabalhos autônomos... estão ligados... com a atividade produtiva dos alunos. São os que mais respondem a uma das tarefas essenciais da escola contemporânea: a formação de uma personalidade criadora [...]" (DAVIDOV, 1988, p. 190, tradução do pesquisador, grifos do autor).

Nessa nova relação com o conhecimento, o escolar consegue pela primeira vez (conscientemente) analisar suas necessidades, compreender e avaliar seus objetivos, planejar suas ações, para realização das tarefas necessárias à obtenção de seus objetivos. O resultado desse processo é o desenvolvimento de neoformações psicológicas que são a base do pensamento e consciência teóricos e as capacidades psíquicas a eles vinculados, como reflexão, análise e planejamento. Essa relação entre a atividade e o desenvolvimento de neoformações é explicitada quando Davidov (1988, p. 231, tradução do pesquisador) afirma que:

\begin{abstract}
A assimilação, pelos escolares de menor idade, dos conhecimentos teóricos no processo de solução de tarefas de estudos mediante as correspondentes ações, exige a orientação para as relações essenciais dos objetos estudados. A realização de tal orientação está ligada com a reflexão, a análise e o planejamento de caráter substancial. Por isso, durante a assimilação pelos escolares de menor idade dos conhecimentos teóricos, surgem condições que favorecem a constituição destas neoformações.

O cumprimento, pelas crianças, das ações de estudos pressupõe a presença da reflexão, da análise e do planejamento substancial. Ao mesmo tempo, algumas ações de estudo estão vinculadas predominantemente com umas ou outras das neoformações citadas.
\end{abstract}

São essas neoformações citadas por Davidov, ao mesmo tempo, fruto da atividade e resultado dela, que 
vão determinar a apropriação do conhecimento científico e, consequentemente, a possibilidade de formação do pensamento teórico nos escolares.

\section{O SUJEITO AUTOR COMO PRODUTO DA ATIVIDADE DE ESTUDO}

Até este momento, foram dadas as bases gerais da concepção de homem e de educação que, implicitamente, contém a concepção de autor, mas, neste momento, é preciso definir o que é ser autor e qual sua relação com a atividade de estudo.

Em sua tese de doutorado intitulada "Atividade de estudo no ensino fundamental: necessidade e motivação", Marino Filho (2011, p. 185) compreende que a autoria ocorre:

[...] somente quando o sujeito da ação é capaz de perceber, discriminar, analisar, categorizar, relacionar, valorizar e incluir um determinado objeto - objetivo da sua atividade - em um campo de significados, num sistema de relações que permitam que ele se localize no fluxo vivo das determinações da sua vida. No caso da escrita, por exemplo, quando um indivíduo sente-se capaz de comunicar para outrem algo que é relevante para si sobre alguma circunstância, ou situação problemática que o afeta, com domínio autoconsciente dos motivos e objetivos, do conhecimento e do uso instrumental dos meios para isso, revela-se a autoria em sua plenitude.

Cabe esclarecer que a autoria é a objetivação da formação integral da consciência em um dado momento, em que situação e condições estão presentes, e expressa uma motivação da personalidade. Isso significa que ocorreu a formação do indivíduo social como sujeito autônomo de sua própria atividade. Isso significa que a autoria é a objetivação do próprio indivíduo, que pode se reconhecer como integralidade no produto de sua atividade.

Pelo exposto na citação acima, para ser autor é necessário que se realize uma atividade que exija desse sujeito a capacidade de perceber o objeto e os objetivos de sua atividade, reconhecer os traços desse objeto, categorizar o que é substancial dos fenômenos e, assim, relacionar os traços essenciais com o todo universal da atividade. Isto é, compreender a função do objeto como prática social significativa. Por essas condições, a autoria é fruto de atividades significativas socialmente para o sujeito, determinadas historicamente.

Nesse contexto, pode-se dizer, a partir das afirmações de Marino Filho (2011), que o processo de autoria é síntese de qualquer atividade humana em que se concretiza o ato autoral, realizado pelo sujeito, de tornar-se parte integrante do gênero humano em todas suas potencialidades, a partir de atos que antes eram coletivos e sociais. Ser autor é o processo constante de se tornar parte da universalidade do gênero humano, ou seja, o processo constante de se tornar humano. Marino Filho (2011, p. 184) compreende o processo de autoria como a "autorrealização do indivíduo" e completa afirmando que ser autor "significa que o indivíduo tornou-se sujeito social e, ao mesmo tempo, efetivo, na sua atividade, em relação aos sentidos pessoais que refletem sua personalidade". No momento de autorrealização, o sujeito se torna consciente, tem autoconhecimento dos caminhos e meios para realizar suas ações na atividade, reflete sobre suas ações, e avalia se esses caminhos são ou não os mais adequados para se chegar ao objetivo da atividade.

Aqui, nota-se a relação entre o processo de autoria e a atividade de estudo para escolares dos anos iniciais do Ensino Fundamental: a atividade de estudo é a ferramenta que possibilita às crianças em idade escolar inicial a apropriação das capacidades necessárias à autoria. Capacidades que são a reflexão, a avaliação, a análise e o planejamento, que são produtos da apropriação do conhecimento teórico como conteúdo da atividade de estudo e formam nos escolares a relação teórica com o mundo.

A avaliação é o processo que tem o papel de verificar e definir se os procedimentos gerais para solução da tarefa estão ou não apropriados, se os resultados das ações realizadas são ou não o esperado pelos objetivos finais traçados. Ser autor implica o processo de constante avaliação dos objetivos e metas, ou seja, as ações de avaliação são fundamentais para o exame qualitativo e essencial do resultado do processo de autoria. Assim, a avaliação na autoria busca confrontar o resultado das ações com a finalidade proposta pelo autor, permitindo ao indivíduo compreender se os resultados propostos foram ou não alcançados. O processo de avaliação é possível graças à capacidade da consciência humana chamada de reflexão, pois, segundo Davidov:

O cumprimento das ações de controle e avaliação supõe que a atenção dos escolares esteja dirigida ao conteúdo das ações próprias, ao exame de seus fundamentos, do ponto de vista da correspondência com o resultado exigido pela tarefa. Semelhante exame, pelos escolares, dos fundamentos das ações próprias, chamado reflexão, conforma a condição essencial para que estas ações se estruturem e mudem corretamente. A atividade de estudo e alguns de seus componentes (em particular, o controle e a avaliação) se realizam graças a uma qualidade tão fundamental da consciência humana como é a reflexão (DAVIDOV, 1988, p. 184, tradução do pesquisador).

Para a atividade de estudo, a capacidade reflexiva é um componente essencial, pois, sem refletir, o sujeito não conseguiria ter a consciência sobre suas limitações, ou ser capaz de compreender e de transformar os limites de suas 
habilidades Além de avaliar se suas necessidades estão sendo supridas pelas tarefas realizadas, e essas ações são todas de natureza reflexiva. Além da reflexão, outros dois processos estão na base orientadora da atividade de estudo: os processos de análise e de planejamento. Davidov (1988, p. 231) afirma que as ações mentais, realizadas no processo de reflexão, análise e planejamento, têm duas formas fundamentais: a empírico-discursiva e a teóricosubstancial. Entende-se que, para serem componentes da atividade de estudos, ações mentais devam estar pautadas nos fundamentos teórico-substanciais, já que o objetivo da atividade de estudo é a transformação qualitativa do sujeito que aprende por meio da apropriação dos conhecimentos teóricos e consequente formação de seu pensamento teórico.

As capacidades de reflexão, avaliação, análise e planejamento teóricos podem ser identificadas como componentes fundamentais da consciência teórica, pois estão na base do desenvolvimento psíquico das crianças que estão entrando nos anos iniciais do Ensino Fundamental. É o desenvolvimento dessas capacidades que vai determinar a restruturação de todas as funções da personalidade e do intelecto infantil.

Do nosso ponto de vista, na base do desenvolvimento psíquico geral dos escolares de menor idade se encontra o processo de formação - no curso da atividade de estudo - da reflexão, da análise e do planejamento teóricos (substanciais), o que determina a reconstrução essencial de toda esfera cognoscitiva e pessoal das crianças (DAVIDOV, 1988, p. 230, tradução do pesquisador).

A reflexão teórica cumpre o papel, no processo da atividade de estudo, de pesquisar e examinar os fundamentos essenciais das ações. Isto é, na reflexão teórica, busca-se, a partir da avaliação dos caminhos tomados, compreender o que de mais substancial tem as ações, o que melhor pode contribuir para que o objetivo da tarefa seja alcançado, podendo continuar o caminho traçado ou replanejar as ações anteriores. Miller (2003, p. 21) demonstra a importância do processo de reflexão teórica para a autoria ao analisar o processo de produção de textos, que implica a realização de atividades epilinguísticas efetivadas por meio das ações de reflexão e operação sobre o texto escrito, afirmando que:

[...] o centro do processo de desenvolvimento, no aluno, da capacidade de produzir textos em conformidade com os usos linguísticos adequados a essa atividade encontra-se nessa apropriação dos saberes socialmente elaborados e do saber-fazer, cuja origem está nas reflexões epilinguísticas e cujo principal mediador é a comunicação interpessoal estabelecida no contexto das ações de ensinar e aprender, que ocorrem numa relação dinâmica e interdependente entre aluno e professor.
A reflexão epilinguística é, pois, o ponto central do desenvolvimento do aluno como autor autônomo de textos escritos.

Outro processo importante, que é base para a autoria e formado na atividade de estudo, é o planejamento teórico, compreendido como o processo pelo qual se organizam os modos e princípios de ação necessários para se chegar ao objetivo da tarefa de estudo. Buscam-se e estruturam-se possíveis conjuntos e sistemas de ações que devem responder de maneira mais adequada e eficaz às necessidades de realização da tarefa de estudo.

Dessa forma, para ser autor, no sentido proposto até aqui, o sujeito deve estar em atividade; Consequentemente, deve realizar o planejamento de suas ações, analisá-las e refletir sobre essas ações para avaliar, durante todo o processo de atividade, se essas ações estão de acordo com o objetivo proposto. Ou seja, a atividade de estudo, por sua estrutura, é ferramenta fundamental para que as crianças em idade escolar tenham a possibilidade de se apropriar da capacidade autoral.

\section{CONSIDERAÇões FinaIS}

A partir das análises feitas, pode-se concluir que a atividade de estudo propicia, em essência, a formação do sujeito autor. É na atividade de estudo e pela apropriação do seu conteúdo, os conhecimentos teóricos, que as crianças em idade escolar inicial podem agir e compreender o mundo de uma nova forma. Forma esta que está baseada nas relações teóricas estabelecidas com o objeto de estudo. É nesse contexto que neoformações psíquicas são formadas nos escolares e possibilitam a constituição do sujeito autor.

Pela primeira vez, ao longo de sua história como indivíduo, de forma consciente, a criança analisa os fenômenos da realidade, planeja suas ações, reflete sobres elas e avalia se estão de acordo com o planejado. Tal processo de constituição da autoria é fruto de uma história de atividades humanas de que o sujeito se apropria. Nesse contexto, o processo de autoria é a síntese de uma história de atividades humanas.

No entanto, a realidade educacional brasileira tem revelado que nem sempre a escola consegue organizar o processo de ensino de modo a concretizar a autoria, pois não tem possibilitado a atividade de estudo e a formação do pensamento teórico nas crianças em idade escolar inicial. Sendo assim, a aprendizagem fica reduzida às relações das crianças com o mundo das apropriações dos conhecimentos empíricos da realidade, que se limitam a compreender a aparência dos fenômenos.

Apenas as relações empíricas com a realidade não possibilitam o processo de constituição do sujeito autor, 
pois não dão conta de desvendar o que é essencial da realidade. A essencialidade do mundo só é possível por ações reflexivas teóricas que se constituem em um fator inerente à constituição da autoria.

Pelas questões expostas até aqui, entende-se que o problema da autoria se resolve pela e na atividade de estudo, pois na criança inserida em atividade de estudo se desenvolvem as capacidades psicológicas superiores relacionadas ao pensar teórico. Estas são ferramentas para o sujeito autor desenvolver meios e caminhos para se constituir como ser genérico humano, autônomo, consciente do processo de constituição de sua humanidade.

\section{REFERÊNCIAS}

DAVIDOV, V. La enseñanza escolar y el desarrollo psíquico. Moscú: Editorial Progreso, 1988.

ELKONIN, D. B. La unidad fundamental de la forma desarrollada de la actividad lúdica. La naturaleza social del juego de roles. In: ILIASOV, I. I.; LIAUDIS, V. Ya. Antología de la psicología pedagógica y de las edades. Habana: Editorial Pueblo y Educación, 1986. p. 74-78.

ELKONIN, D. B. Sobre el problema de la periodización del desarrollo psíquico en la infancia. In: SHUARE, M. La Psicología evolutiva y pedagógica en la URSS - Antología. Moscú: Editorial Progreso, 1987. p. 104-124.

FOUCAULT, M. O que é um autor? In: FOUCAULT, M. Estética: literatura e pintura, música e cinema. Organização e seleção de textos: Manoel Barros Mott: tradução de Inês Autran Dourado. 2. ed. Rio de Janeiro: Forense Universitária, 2006. p. 264-298. (Coleção Ditos e Escritos, III).
LEONTIEV, A. N. Actividad y conciencia. In: LEONTIEV, A. N. Actividad, conciencia y personalidad. Buenos Aires: Ediciones Ciencias Del Hombre, 1978.

LEONTIEV, A. N. O desenvolvimento do psiquismo. 2. ed. São Paulo: Centauro, 2004.

LEONTIEV,A. N. Uma contribuição à teoria do desenvolvimento da psique infantil. In: VIGOSTKII, L. S.; LURIA, A. R.; LEONTIEV, A. N. Linguagem, desenvolvimento e aprendizagem. 10. ed. Tradução de Maria Penha Villalobos. São Paulo: Ícone: Universidade de São Paulo, 2006. p. 59-83.

MARX, K.; ENGELS, F. A ideologia alemã. São Paulo: Martins Fontes, 2002.

MARINO FILHO, A. A atividade de estudo no ensino fundamental: necessidade e motivação. 2011. 237 f. Tese (Doutorado em Educação) - Faculdade de Filosofia e Ciência, Unesp, Marília, 2011.

MILLER, S. Sem reflexão não há solução: o desenvolvimento do aluno como autor autônomo de textos escritos. In: MORTATTI, M. do R. Atuação de professores: propostas para ação reflexiva no ensino fundamental. Araraquara, SP: JM Editora, 2003. p. 9-22.

ORLANDI, E. P. Discurso e leitura. São Paulo: Cortez; Campinas, SP: Editora da Universidade de Campinas, 2000.

SILVA, O. S. F. Entre o plágio e a autoria: qual o papel da universidade? Rev. Bras. Educ. [online]. Rio de Janeiro, v. 13, n. 38, p. 357-368, maio/ago. 2008. ISSN 1413-2478. Disponível em: <http://dx.doi.org/10.1590/S1413-24782008000200012>. Acesso em: 12 out. 2013.

TFOUNI, L.V. Múltiplas faces da autoria. Ijuí: Ed. Unijuí, 2008.

Submetido em: 05/01/2016

Aprovado em: 11/01/2016 